\title{
Why homicide clearance rates decrease: evidence from the Caribbean
}

\author{
Edward R. Maguire ${ }^{\mathrm{a} *}$, William R. King ${ }^{\mathrm{b}}$, Devon Johnson ${ }^{\mathrm{c}}$ and Charles M. Katz ${ }^{\mathrm{d}}$ \\ ${ }^{a}$ Department of Justice, Law and Society, American University, 4400 Massachusetts Avenue, \\ NW, Washington, DC 20016, USA, ${ }^{b}$ College of Criminal Justice, Sam Houston State University, \\ Box 2296, Huntsville, TX 77341, USA; ${ }^{c}$ Department of Criminology, Law and Society, George \\ Mason University, 4400 University Drive, MS 4F4, Fairfax, VA 22030, USA; ${ }^{d}$ School of \\ Criminology and Criminal Justice, Arizona State University, $4701 \mathrm{~W}$. Thunderbird Road, \\ P.O. Box 37100, Phoenix, AZ 85069, USA
}

(Received 7 October 2009; final version received 12 April 2010)

\begin{abstract}
Police agencies and researchers have devoted significant attention to understanding and improving homicide clearance rates, which often serve as an overall barometer of police performance. Using quantitative and qualitative data, this study examines the factors that contributed to a rapid decline in homicide clearances in the developing island nation of Trinidad and Tobago. A variety of explanations are explored, including characteristics of homicide incidents, the communities where they occur, and the agencies that process these cases. The findings indicate that substantial changes in the nature of homicides, combined with insufficient organisational capacity within the criminal justice system to detect and respond to these changes, explain the declining homicide clearance rate. Theoretical explanations for homicide clearances must represent a blend of insights from criminology and organisational science to account for both the offence itself, as well as how it is processed by the police and other agencies.
\end{abstract}

Keywords: homicide; clearance rate; Caribbean criminology

\section{Introduction}

Homicide clearance rates are often used as a yardstick for measuring overall police performance. Investigations constitute only a small share of what the police do, but homicide clearance rates often serve as a proxy for police performance for two reasons. First, most people would agree that murder is the most serious type of crime, and therefore solving murder cases is among the most important of police functions. Bringing a murderer to justice quenches the public's thirst for the police to do something about violent crime. Second, homicides are the most reliably reported crime. Measurement error in official police data on other crime types is often so severe that it is difficult to know whether increases or decreases represent true changes in crime or are simply an artefact of reporting or recording practices (Hoffman 1971, Nadel 1978, Poggio et al. 1985, Cordner 1989, Alpert and Moore 1993, Riedel and Jarvis 1998). Although homicide clearances are sometimes conceptually ambiguous, they are much less ambiguous than clearances for other crime types. ${ }^{1}$

*Corresponding author. Email: maguire@american.edu 
Police agencies expend great effort attempting to achieve high homicide clearance rates. Researchers have also devoted much attention to understanding homicide clearance rates and the factors that influence them. The quest to understand and improve homicide clearances has led to a bifurcated body of knowledge. Police draw upon their training and experiences to develop their own assumptions and opinions, typically not validated by research, about what factors influence clearances. In contrast, academic research on the topic is more systematic, but is generally not very useful to those responsible for improving homicide clearances.

This paper attempts to bridge the gap between these two sources of knowledge about homicide clearances. We draw on data from Trinidad and Tobago, a two-island Caribbean nation of 1.26 million people located 7 miles off the north-east coast of Venezuela. Trinidad and Tobago experienced a serious increase in homicides from 1999 to 2005, but in that time its clearance rate decreased dramatically. Officers and leaders of the Trinidad and Tobago Police Service (TTPS) embrace a number of explanations for the increase in homicides and the decrease in clearances. Implicit in these explanations are some hypotheses that have been tested in previous research in other jurisdictions, and other hypotheses that until now remain untested. The rapid and pronounced decrease in homicide clearance rates in Trinidad and Tobago, combined with our wide-ranging access to people and data within the TTPS, provides a unique opportunity to understand the factors that contribute to a decline in clearances. As part of a project funded by the Government of Trinidad and Tobago, we conducted a series of studies on the nature of the violence problem in Trinidad and Tobago as well as official responses to violence. One part of that larger project involved collecting and analysing data that would enable us to sort through competing explanations for the decline in homicide clearances.

The findings from our research in Trinidad and Tobago illuminate a number of factors that contributed to the decline in clearance rates. Policy-makers can manipulate some of these factors, but others cannot be as easily influenced. We situate our findings within a larger context of research and theory on the capacity of organisations, systems and governments to organise and mobilise to prevent and respond to large-scale social problems.

We begin the paper by defining homicide clearance rates and describing the various pathways through which a case can be cleared. We then draw on organisational theory to illustrate how homicide clearances represent an output for police organisations that is influenced by their environment and their technology. ${ }^{2}$ Next, we briefly review the research evidence on homicide clearances and the factors that influence them. We then provide a brief history of both homicides and clearances in Trinidad and Tobago. We draw on both quantitative and qualitative evidence to explain the decrease. We conclude with the implications of the Trinidad and Tobago experience for general knowledge on homicide clearances. The characteristics of homicide cases exert a strong influence on clearance rates, but so too do the people, organisations and systems responsible for processing these cases.

\section{Defining homicide clearance rates}

Once a suspicious death has been ruled a homicide, the police typically clear the case in two ways: by arrest or by 'exception' (Poggio et al. 1985). A homicide is cleared by exception when the police know the identity of the offender but are unable to make 
an arrest for any of a number of reasons, such as the offender is dead or in the custody of other officials (in a different country, for instance), or the charges were rejected by the prosecutor. Exceptional clearances are also sometimes referred to as 'administrative closures'.

The TTPS uses the term 'detection rates' rather than 'clearance rates', though the two terms are equivalent. In the TTPS, detections and detection rates are used as the primary measure of successful homicide investigations. Homicides are considered detected in only two circumstances - when the suspect is charged with a homicide, or when a suspect has been linked with a past homicide but dies before he or she can be charged. In cases where the suspect dies, the homicide personnel with whom we spoke claimed that they would require eyewitnesses to identify the suspect's body before they would classify the case as detected. Cases are rarely classified as detected in this way. Finally, the few cases in which the suspect flees the country (sometimes called 'known but flown' in the USA) are not generally considered detected, but rather remain open as undetected cases. For the remainder of the paper we will use the term clearance rates instead of detection rates to remain consistent with the literature.

\section{Homicide clearance rates as organisational outputs}

Some of the factors that influence homicide clearance rates are external to the police organisation, such as the nature of homicide cases or the weapon types chosen by offenders. Other factors are internal to the organisation, such as the number of investigators or the adequacy of their policies and procedures. In the parlance of organisational scholars, the former set of factors characterises the organisation's environment, while the latter constitutes its technology (Langworthy 1986, Maguire 2003). The organisation's environment constitutes everything that is external and upon which it relies for resources, legitimacy, support, information and raw materials, among other factors. An organisation's technology is internal and consists of all the methods used to transform inputs or raw materials into outputs. Note that although conventional use of the term technology conjures images of material gadgets, organisational scholars use the term more broadly to refer to organisational processes that can be human or social as well as material (Hasenfeld 1992, Maguire 2003).

All organisations - whether public or private, profit or non-profit, manufacturing or service - take some raw material or input, process it using some technologies (which may be material, electronic or social), and transform it into some output. Viewed in organisational terms, the raw material or input in a homicide bureau is an unsolved murder case. The clearance itself represents the ultimate output. The technology consists of all the internal processes used by the organisation to transform inputs into outputs, or put another way, to transform unsolved cases into solved cases. All of the factors external to the organisation that influence its ability to solve cases are a part of the organisation's environment.

The essential challenge for any organisation is to adapt its technologies to its environment. This is one of the basic premises of contingency theory, which posits that effective organisations must maintain a proper fit with their environment (Donaldson 1995, Maguire 2003). The problem for some organisations is that their environments are often complex and dynamic. Turbulent, heterogeneous, dynamic 
environments are difficult to analyse and predict; organisations situated in such environments face the constant challenge of trying to keep up and maintain fit. Some environments present an even more challenging problem for organisations when they go through intermittent cycles of stability and change. During periods of environmental stability, organisations can easily slip into complacency and out of fit, allowing periods of environmental change to take them by surprise.

For organisations to maintain a fit with their environment, they must have the capacity to adapt. This adaptive capacity is shaped by two primary factors: whether the organisation has an effective mechanism for detecting changes in the environment, and whether it has the ability and the will to institute change when the need is detected. Adaptive capacity is also shaped to some extent by what we will call 'environmental imperative'. A business that experiences a sharp decline in customer revenues must change if it is to survive. Think of mainframe computer manufacturers at the dawn of the personal computer era, or of the small mom-and-pop stores in communities where a new 'superstore' like Target or Wal-Mart opens.

Yet many public organisations, like police agencies, are unlikely to go out of business. There is less of a cost for failing to adapt. ${ }^{3}$ For this reason, police organisations have been likened to a class of organisations that Meyer and Zucker (1989) have termed 'permanently failing organizations'; they persist even when they routinely show suboptimal performance. Several scholars have now applied institutional theory to police organisations, arguing that they tend to adapt by implementing ceremonial or symbolic changes rather than rational, substantive changes genuinely intended to improve performance (Crank and Langworthy 1992, Katz 2001, Crank 2003, Willis et al. 2007). Contingency theory is concerned with how organisations maintain fit with their environments. Institutional theory is concerned with how they maintain the illusion of fit. This paper draws on concepts and theories from the study of organisations and public agencies to frame our examination of homicide clearance rates.

\section{Research on homicide clearance rates}

Despite their popularity as a measure of police performance, homicide clearances have only recently become the subject of systematic, empirical research. Prompted by the decline in homicide clearance rates in the USA in the last few decades, researchers began to examine the factors that increase (and decrease) the likelihood that homicide cases will be solved. To date most research in the English language has been done in the USA, although a handful of studies have been conducted in other developed countries. For example, Innes (2003) examined homicide clearance rates in England and Wales, Mouzos and Muller (2001) examined homicide clearance rates in Australia, and researchers have conducted cross-national comparisons between the USA and Canada (Regoeczi et al. 2000) and the USA and Japan (Roberts 2008). In addition, some studies directly attempt to explain the decline in homicide clearance rates over time (Davies 2007, Litwin and Xu 2007, Xu 2008).

Generally, quantitative research on homicide clearance rates has followed one of three tracks. Individual level studies treat homicide cases as the unit of analysis and examine the influence of case characteristics on clearances. Thus, the dependent variable in these studies is binary - whether the case was cleared or not. Aggregatelevel studies treat cities as the unit of analysis and examine the influence of 
jurisdiction (including community and agency) characteristics on clearance rates. In these studies, the dependent variable is continuous, typically expressed as the proportion of cases that were cleared. Multilevel studies combine the features of individual and aggregate studies, treating homicide cases as the unit of analysis, but including case and jurisdiction characteristics as explanatory variables in multilevel models.

Given the nature of the research, making firm conclusions about the factors related to homicide clearances is problematic. This is partly because studies of homicide clearance rates have used different levels of analysis, as described above, but also because they have employed many explanatory and analytical frameworks, examined different jurisdictions and have generally produced inconsistent results. Nevertheless, researchers have identified a variety of factors that may influence the likelihood that homicide cases will be cleared. While most of this research is applied, with little testing or development of theory, we do think these factors can be distilled into two conceptually meaningful domains within which theory can be developed: environmental factors and organisational factors. For instance, Innes (2003, p. 15) argues that to understand detective work, it is important to 'understand the ways in which it is ordered by the organization and...the environment that frames the organization'.

\section{Environmental factors}

Environments provide organisations with raw materials and inputs. Decades of research in organisation theory have reinforced the notion that environments can exert powerful influences on organisations (Langworthy 1986, Maguire 2003). Turbulence or sudden change in the environment can penetrate the organisation and introduce instability. Therefore it is no surprise that research on homicide clearances has focused so intently on the explanatory role of environmental characteristics.

Researchers have shown that case characteristics such as the demographic background of the victim, the weapon used and the circumstances surrounding the murder influence the probability that a homicide will be solved. The race, age and gender of victims are often significant predictors of homicide clearances (Wellford and Cronin 1999, Regoeczi et al. 2000, Puckett and Lundman 2003, Litwin 2004, Lee 2005, Addington 2006, Roberts 2007, Jiao 2008, but see Riedel and Rinehart 1996). For instance, North American research has shown that cases involving non-white, younger and female victims are more likely to be solved than cases involving whites, older or male victims. The theoretical or conceptual meaning of these findings is not always explored by researchers finding such effects, but some do place their research in a theoretical context (e.g. Lee 2005, Roberts 2007). Generally, demographic variables are thought to contribute to 'solvability'. For instance, one explanation for the relationship between demographic variables and clearances may be that they are correlated with case type (e.g. young African-American or Afro-Caribbean males as victims of gang homicide, females as victims of domestic homicide, etc.). Another may be that they influence the level of witness cooperation with investigators (e.g. with residents of some neighbourhoods too frightened or alienated to talk to the police). Research has not done a good job of parsing these theoretical explanations for the effects of victim demographics on clearances. It is also unclear how findings 
from the predominantly white societies where the research has been conducted translate to nations, like Trinidad and Tobago, with other racial distributions and dynamics.

The results for weapon type are mixed. Some studies find that murders committed with guns are less likely to be solved than homicides committed with other types of weapons (Regoeczi et al. 2000, Litwin 2004, Addington 2006, Alderden and Lavery 2007, Roberts 2007), but other studies find that weapon type does not have a significant effect on clearances (Riedel and Rinehart 1996, Jiao 2008). The underlying theoretical proposition is that homicides committed with sharp objects, blunt objects or strangulation/asphyxiation are typically more personal than homicides committed with firearms. Homicides committed in a more up-close and personal way are thought to be more solvable because the offender will often leave more physical evidence behind, and because he or she is more often known to the victim.

In addition, the circumstances surrounding the murder matter. Murders committed with a concomitant felony are less likely to be solved than other types of homicides (Riedel and Rinehart 1996, Regoeczi et al. 2000, Lee 2005), as are homicides that are drug- or gang-related (Wellford and Cronin 1999, Litwin 2004), but see Roberts (2007), who found higher clearance rates for murders with these three characteristics. Similarly, homicides committed in public locations are less likely to be solved than murders committed in private locations (Wellford and Cronin 1999, Litwin 2004). Once again, all of these factors represent crude indicators of a case's solvability.

Multilevel and aggregate studies have examined the influence of political environment and community characteristics on homicide clearance rates. One study found, for instance, that the percentage of a city's expenditures on policing had no effect on aggregate clearance rates (Borg and Parker 2001). Another found that the political environment in which police agencies operate influences homicide clearance rates in some situations (Davies 2007). A number of studies at the aggregate level have tested Black's (1976) theory of law in the context of homicide clearance rates. Black (1976) theorises that the nature and amount of governmental social control is a function of the status characteristics of individuals (such as victims and offenders) or places (such as neighbourhoods or communities). Again, some of the findings are inconsistent. Borg and Parker (2001) examined clearance rates in US cities with populations over 100,000 , and found that racial residential segregation, percentage of persons with a high school degree and percentage of a city's expenditures for education all had a positive effect on clearance rates, while residential mobility and the city's homicide rate had a negative impact. Litwin (2004) found that area homeownership rates had a positive impact on clearance rates, while area income, unemployment, educational attainment, population and homicide rate each had no effect on the proportion of homicides that were solved. The underlying conceptual basis of this research seems to be that people and places with less social status will get less justice.

\section{Organisational factors}

Police practices and investigative procedures - the technologies used by police agencies - are also key predictors of clearance rates. Wellford and Cronin's (1999) 
analysis of 215 possible factors related to homicide clearances highlighted the importance of a quick response and comprehensive investigative practices on the part of the police. They found that clearance rates are higher when the first officer on the scene notifies all relevant agencies (homicide squad, medical examiner's office and crime lab), secures the area and locates witnesses. Homicide cases are also more likely to be solved when more than one detective is assigned to the case, when detectives take detailed notes about the murder scene and when they follow up on all witness information. Interviewing witnesses at the crime scene, as well as family, friends or acquaintances of the suspect and victim, also increases the likelihood that detectives will solve the crime. Taken together, these findings illustrate that how police organisations position themselves to investigate homicides has an enormous influence on clearance rates.

Multilevel and aggregate research indicates that characteristics of the police organisation affect clearance rates, but in some cases the findings are mixed. Characteristics of police organisations that have been examined in this line of research include detective experience and training, detective workload and police expenditures. Chaiken et al. (1977) and Puckett and Lundman (2003) each find that detective experience is unrelated to homicide clearances; in contrast, detective experience is positively related to homicide clearance in Marche's study (1994), especially for larger police jurisdictions. Similarly, though Marche (1994) reports a negative relationship between detective workload and clearance rates, Puckett and Lundman (2003) find no significant relationship. Finally, Keel et al. (2008) find that formal training of homicide detectives is associated with improved clearance rates. Once again, the theoretical or conceptual meaning of these variables is typically not explored.

What is missing from this research is any kind of systematic review of investigative practices that do not influence clearance rates. For instance, many nations now place great faith in sophisticated investigative technologies like ballistic imaging, automated fingerprint systems and DNA analysis. While there is a lot of anecdotal evidence on the effectiveness of these and other technologies, there is no research to suggest that the police are now any better at solving homicides than they were before these technologies were available. A recent study found that New York City homicide investigators made very little use of DNA analysis even when they gathered evidence samples from the crime scene that were appropriate for such analysis (Schroeder and White 2009). More broadly, the quest to identify the full range of police practices and investigative procedures that correspond with high clearance rates faces a number of methodological challenges (see Addington 2006). The effects of these factors are presumably interactive, not independent. Most have also not been studied systematically. Thus we suspect that between selection effects, complex interaction effects and other methodological challenges, much remains to be learned.

\section{Overview}

Despite these limitations, research on the factors influencing homicide clearances provides some explanation for why rates increase or decrease over time. Changes in the types of homicides, the number of homicides or the quality of police-community relations, for instance, may affect homicide clearance rates over time (Riedel and 
Jarvis 1998, Litwin and Xu 2007, Xu 2008). For example, murders that involve guns, that are related to drugs or gangs, or that occur between strangers are more difficult to solve than murders between individuals with some pre-existing relationship, murders committed with weapons that require more personal contact and murders with other motives. Given the findings of previous research, we would expect an increase in homicides with these types of characteristics to produce a decrease in clearance rates. Similarly, the presence of witnesses and the willingness of those witnesses to assist the police is a key predictor of homicide clearances (Riedel and Rinehart 1996, Riedel and Jarvis 1998, Wellford and Cronin 1999, Keel et al. 2008). Thus, a breakdown in police-community relations, a lack of trust in the police, or a growing fear of retaliation among witnesses would likely lead to a decrease in the number of solved homicides.

Nearly all of the research on homicide clearances has taken place in the USA. A handful of studies come from other developed nations. This is the first published study in the English language, to our knowledge, that examines homicide clearances in a developing nation. One of the common characteristics of developing nations is difficulty in mobilising state institutions to plan and act quickly and responsively (Riggs 1964). These issues become even more difficult when attempting to coordinate a system that includes multiple organisations. We have argued that although homicide clearance rates are influenced by external phenomena, they are also an organisational product. While there is variation in the structure and practice of homicide investigations within developed nations, the variation is much more pronounced when we widen the scope of the research to include developing nations.

\section{Data and methods}

Data for this study were collected from December 2004 to March 2006 by a team of researchers working regularly in Trinidad and Tobago. Our work within the TTPS was sponsored by the Ministry of National Security, which allowed us unfettered access to all elements of Trinidad and Tobago's criminal justice system and enabled us to collect a wide-ranging set of qualitative and quantitative data. During the study period the authors spent approximately 240 days in Trinidad and Tobago studying crime and criminal justice issues. We rely on three primary sources of data for this paper, though other supplemental data sources are used briefly in some sections.

First, we collected several forms of 'official' data from the Homicide Bureau of Investigations (HBI) within the TTPS. This included historical data on staffing from 1988 to 2005 , summary data on homicides by weapon type from 1988 to 2005 and detailed incident and victim-level data from the Homicide Bureau's offence register for all homicides from 2001 to 2005. The latter data source contains descriptive information on offender, victim, incident and case-processing characteristics. Most data from the Homicide Bureau were recorded in handwritten logbooks; we manually extracted the various forms of data and entered them into electronic databases.

Second, we conducted a total of 242 interviews with 113 different people. These included 131 interviews with 62 employees from various units and divisions throughout the TTPS, including administrators, uniformed constables, general criminal investigators, homicide detectives, crime analysts and intelligence officers. Interviews focused on the officers' perspectives on their work, the nature of the 
organisation, management and supervisory practices, and the reasons for the increase in homicides and decrease in clearances. In addition, we conducted 52 interviews with 23 people from other criminal justice agencies, including the Ministry of National Security, the crime laboratory, the prisons, the courts and other defence and intelligence agencies; 21 interviews with 13 people from other (not criminal justice-related) government agencies; seven interviews with five gang leaders and two gang members; and 31 interviews with eight other people, including community activists and members of the faith community. These interviews fell in the middle of the continuum between unstructured and semi-structured in the sense that the research team was focused on four specific themes: the nature and causes of the nation's outbreak of violence; the institutional capacity of the police and other agencies to address the violence; the internal and external causes of the violence; and the role and experiences of the person being interviewed in relation to the violence problem. On top of the interviews we conducted with individuals, we also held a focus group with residents of a distressed, inner-city community that had experienced a large number of homicides.

Third, we conducted unsystematic observations that were primarily intended to familiarise the research team with the agency and its personnel. We accompanied task force officers and criminal investigators on nine ride-alongs in the distressed urban communities where most of the homicides take place. During these ridealongs, we observed officers on patrol, investigating crimes, conducting searches, planning operations, interviewing victims and suspects and arresting offenders. We also attended six homicide scenes, where we were given complete 'insider' access to all personnel and where we were able to speak briefly with witnesses as well as friends and family of the victims (these brief, unplanned conversations are not included in the list of interviews above). We also toured the crime laboratory and observed forensic examiners carrying out their work. We toured five police evidence storage facilities, where we were able to observe evidence storage practices. We attended eight meetings of the Homicide Prevention Working Group where representatives from multiple agencies discussed open homicide cases and attempted to resolve issues standing in the way of clearing those cases. We also observed a gang truce meeting organised by a local priest in the aftermath of several murders. The truce meeting, which was attended by several gang leaders and police officers, was intended to reduce active conflict between four warring gangs (our conversations with the attendees at this meeting are also not included in our tally of interviews above).

In addition to the three primary categories of data just discussed, we also drew on a handful of supplementary data sources in different sections of the paper. First, we met with investigators, intelligence officers and task force officers in two police districts multiple times to gather intelligence about homicide cases. We learned from these interviews that the officers frequently had detailed information about both suspect and motive, typically from informants. However, in many instances, they were unable to use this information to clear cases because witnesses refused to testify or other problems emerged. We use this homicide intelligence to illustrate the problems with 'official' motives assigned by the Homicide Bureau. Second, we obtained data on evidence processing from the nation's crime laboratory. We use the data to examine evidence processing delays. We also took part in hundreds of informal conversations with arrestees, inmates, police officers, prosecutors, judges, forensic scientists, community leaders, residents, witnesses, victims and gang 
members about the nature of the crime problem in Trinidad and Tobago. These conversations typically took place in meetings, between meetings or during social events. They do not constitute formal 'interviews', but when we were able to obtain useful information from these conversations, we recorded it in our field notes.

The paper draws on a variety of quantitative and qualitative data sources. Whenever quantitative data are available, we use statistical methods to test potential explanations for the decline in homicide clearances. In some instances, quantitative data are unavailable, but we are able to draw on a rich collection of qualitative data. We took detailed field notes during all of our interviews and observations. We then used ATLAS/ti qualitative data analysis software to organise, code and analyse our field notes and extract meaningful themes from the data (Ryan and Bernard 2000). Although we lack the data to carry out a thorough and compelling analysis of every potential explanation for the decline in clearances, the various data sources we draw upon, taken together, provide a strong, circumstantial case for the conclusions we reach.

\section{Homicide trends in Trinidad and Tobago}

From 1988 to 1998, the number of homicides in Trinidad and Tobago remained fairly stable, averaging approximately 106 homicides per year. After 1999, homicides increased sharply; the number of murders rose from 93 in 1999 to 385 in 2005, a $314 \%$ increase. Despite the massive increase in the number of homicides, the number of cleared cases remained fairly stable. From 1990 to 1998, for instance, the number of clearances averaged about 68 per year. The average detection rate during this period was approximately $66 \%$. From 1999 to 2005, a period of substantial increase in homicides, the raw number of clearances averaged just 76 per year. The average detection rate during this period dropped to just over $44 \%$, hitting a low of about $24 \%$ in 2005 . Figure 1 illustrates the raw numbers of homicides and clearances from 1988 to 2005 . Most notable is the extent to which these two numbers began to diverge substantially in 2000 when homicides began to increase but clearances did not follow. Figure 2 illustrates clearance rates from 1988 to 2005. Of importance here is the steady decline from just over $70 \%$ in 1999 to $24 \%$ in 2005 .

\section{Explaining the decline in clearance rates}

Taken together, the findings of previous research and the explanations articulated by Trinidad and Tobago police officials provide a useful starting point for identifying factors that led to the decline in homicide clearances. In this section we examine three broad categories of explanations: environmental factors, organisational factors and higher order effects. Environmental factors include case characteristics, the willingness of citizens to cooperate with investigators, and the nature of prosecutorial and judicial decision-making. Organisational factors include staffing, investigative characteristics and forensic evidence processing capacity. Higher order effects represent multiplicative interactions or nonrecursive relationships between environmental and organisational factors. Our exploration of these effects draws on multiple sources of evidence, both qualitative and quantitative. In some cases the data permit clear inferences and in other cases, data limitations make it difficult to draw firm conclusions. 


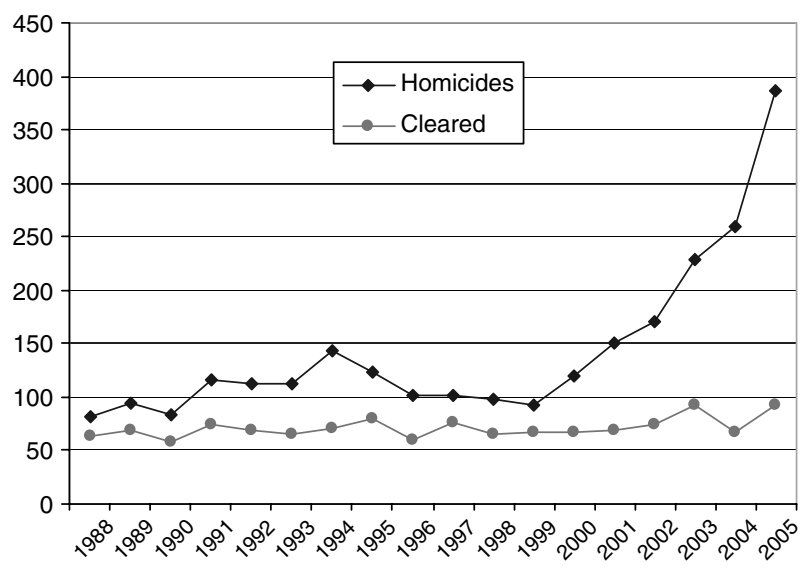

Figure 1. Raw number of homicides and clearances in Trinidad and Tobago, 1988-2005.

\section{Environmental factors}

\section{Case characteristics}

Previous research has shown that homicides committed with firearms are usually more difficult to solve than homicides committed using other weapons. We were able to obtain summary data on homicides by weapon type from 1988 to 2005 . Figure 3 shows that most of the increase in homicides is attributable to homicides by firearm. Although we do not have sufficient data to conduct a careful multivariate statistical analysis, the simple bivariate correlation between the number of homicides by firearm and homicide detection rates from 1988 to 2005 suggests a strong negative relationship $(r=-0.91) .{ }^{4}$ This finding, together with data from our observations and interviews, suggests that the growth in firearms homicides contributed substantially to the reduction in clearances. Our interviews with investigators, community

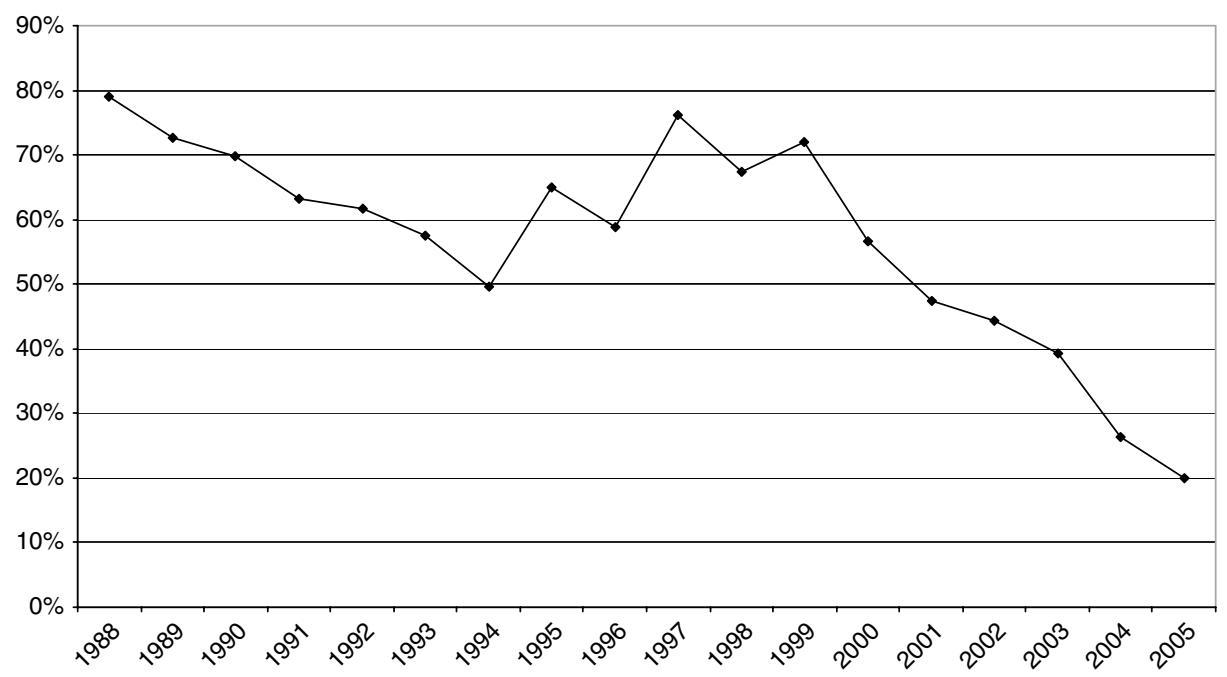

Figure 2. Homicide clearance rates in Trinidad and Tobago, 1988-2005. 


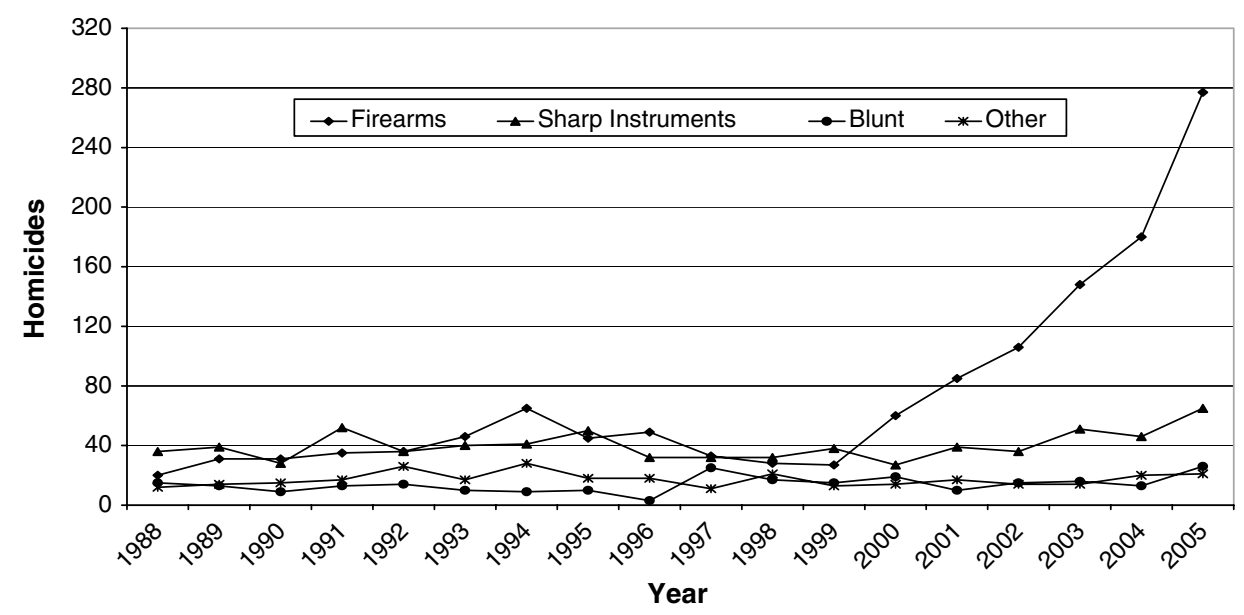

Figure 3. Homicides by weapon type, 1988-2005.

members, gang members and gang leaders revealed this dramatic increase in firearms homicides to be a product of escalating gang warfare. Guns are the weapon of choice for gang members, and gang homicides are among the most difficult to solve for several reasons: witness reluctance to cooperate with the police, little physical evidence and a tendency among gangs to settle their own conflicts without invoking the legal system (Maxson et al. 1985, Maguire et al. 2008).

Given our hypothesis that the growth in homicides committed with firearms is due to an increase in gang-related killings, one might expect that we could test this hypothesis by looking at data on homicide motives. Unfortunately, we have serious doubts about the validity and reliability of official police classifications of homicide motives within the TTPS - especially for certain categories such as gang and drugrelated homicides, as well as altercations. Other categories, such as domestic and robbery homicides, appear to be more clear-cut and easier for officers to classify. ${ }^{5}$ Consequently, we offer the results of this analysis with a strong caveat about the interpretability of findings.

Previous research suggests that the motive for a homicide has a strong influence on whether police are able to clear the case (Maxson et al. 1985). Table 1 shows the percentage of homicides by motive each year from 2001 to 2005 . $^{6}$ Four findings are evident from this table. First, drug-related homicides dropped from $24.6 \%$ in 2001 to

Table 1 . Homicides by motive, 2001-2005.

\begin{tabular}{ccccccccc}
\hline Year & $\begin{array}{c}\text { Domestic } \\
(\%)\end{array}$ & $\begin{array}{c}\text { Robbery } \\
(\%)\end{array}$ & $\begin{array}{c}\text { Drug- } \\
\text { related } \\
(\%)\end{array}$ & $\begin{array}{c}\text { Gang- } \\
\text { related } \\
(\%)\end{array}$ & $\begin{array}{c}\text { Revenge } \\
(\%)\end{array}$ & $\begin{array}{c}\text { Altercation } \\
(\%)\end{array}$ & $\begin{array}{c}\text { Other } \\
(\%)\end{array}$ & $\begin{array}{c}\text { Proportion } \\
\text { known }(\%)\end{array}$ \\
\hline 2001 & 12.3 & 23.0 & 24.6 & 8.2 & 8.2 & 24.6 & 3.3 & 80.8 \\
2002 & 10.6 & 23.2 & 12.0 & 21.1 & 2.8 & 24.6 & 4.9 & 83.0 \\
2003 & 7.0 & 19.1 & 7.0 & 26.1 & 7.0 & 30.4 & 3.5 & 50.7 \\
2004 & 6.1 & 25.8 & 9.8 & 33.7 & 5.5 & 16.6 & 2.5 & 62.7 \\
2005 & 11.8 & 20.4 & 8.6 & 30.1 & 4.8 & 18.8 & 4.8 & 48.1 \\
\hline
\end{tabular}


$8.6 \%$ in 2005. Second, gang-related homicides increased from $8.2 \%$ in 2001 to $30.1 \%$ in 2005. Third, changes in other types of homicides are erratic, with no clear visible pattern. Finally, as the last column illustrates, the proportion of cases in which the motive is known decreased from $80.8 \%$ in 2001 to $48.1 \%$ in 2005.

We believe these figures underestimate the degree of gang involvement in homicides. For instance, based on interviews with police gang specialists, we gathered detailed intelligence data on homicides occurring in two high-crime station districts. In one, intelligence suggested that $60 \%$ of the homicides were gang-related, compared with an official classification of gang-related homicides of $23.8 \%$. In the other, intelligence suggested $63.6 \%$ were gang-related, compared with an official classification of $30.2 \%$. Thus, although we do not have systematic data from police intelligence sources on the motives or causes of homicides throughout Trinidad and Tobago, we do have strong evidence from two communities that these official police classifications represent substantial underestimates of gang-related homicides. We also believe that the official classifications underestimate growth in gang-related homicides. The proportion of cases containing an unknown motive has increased substantially, and our intelligence data reveal that most cases with an official motive of 'unknown' are gang-related.

Previous research also shows that the location where a homicide occurs, as well as the relationship between the victim and the offender, exerts a strong influence on whether the case is cleared. Our interpretation of the literature is that this finding is commingled with motive. In North America, homicides that occur indoors are often committed by an acquaintance of the victim rather than a stranger. The drive-by shooting, in which the victims are usually shot outdoors, became a cultural icon of gang violence in the USA in the 1980s and 1990s. Indoor locations also tend to preserve physical evidence better than external locations, where weather, traffic, dirt and rough surfaces make it more difficult for investigators to discover clean, wellpreserved pieces of evidence. Thus for several reasons, indoor homicides may be easier to clear than outdoor homicides. Table 2 shows homicide locations by year from 2001 to 2005 . On average, about $66 \%$ of homicides in Trinidad and Tobago occur outside, about $26 \%$ occur inside a building and about $8 \%$ occur inside a vehicle. We are unable to discern any clear or systematic changes in this pattern, therefore we view it as an unlikely explanation for the decline in clearance rates.

Although victim-offender relationships are thought to exert an important influence on homicide clearances, this relationship is unknown for the vast majority of cases in Trinidad and Tobago. Between 2001 and 2005, the victim-offender relationship was known in an average of $11.1 \%$ of cases per year, ranging from a low

Table 2. Homicide rates by location, 2001-2005.

\begin{tabular}{lccc}
\hline Year & Outside $(\%)$ & Inside $(\%)$ & Vehicle $(\%)$ \\
\hline 2001 & 61.9 & 26.5 & 11.6 \\
2002 & 68.5 & 25.0 & 6.5 \\
2003 & 61.2 & 29.2 & 8.7 \\
2004 & 68.7 & 24.2 & 7.5 \\
2005 & 70.3 & 22.7 & 7.0 \\
\hline
\end{tabular}

Note: Unknown locations have been excluded from these calculations. 
of $4.2 \%$ in 2004 to a high of $17 \%$ in 2002 . With so much missing data, we are unable to draw any clear inferences about the effects of victim-offender relationship on homicide clearances.

Previous research has also shown that demographic characteristics of the victim, such as age, sex and race also have an impact on homicide clearances. Table 3 shows the age of homicide victims by year from 2001 to 2005 . The changes within each age category are subtle, with an increase in the proportion of victims aged 15-24 and a decrease in those under 15 or over 45 . Overall, the mean age of homicide victims decreased from 35.7 in 2001 to 31.4 in 2005. Once again, we view this subtle change as indicative of the increase in killings of young gang-aged men. Table 4 shows the sex of homicide victims by year. On average, about $13 \%$ of homicide victims each year are female and $87 \%$ are male. We observe a small pattern in which the proportion of women as homicide victims is decreasing while the proportion of men is increasing. Homicide victim race is recorded erratically by the TTPS. In 2001 and 2002, for instance, victim race was recorded in approximately $3 \%$ of cases. By 2003 , this figure had risen to about $98 \%$ of cases. By 2004 it dropped to $91 \%$, and by 2005 it reached $80 \%$. Due to missing data we are unable to draw any clear inferences about the effects of victim race.

\section{Willingness of citizens to cooperate with investigators}

Our interviews with numerous police officers and investigators revealed that many citizens are unwilling to cooperate with police investigators. We uncovered two reasons for this unwillingness: fear and distrust of the police, and fear of reprisal from criminals. According to police investigators, as the number of homicides increased and clearance rates declined, the public lost confidence in the ability of the police to identify and apprehend murderers and many citizens became afraid to help the police with investigations. In some high-crime neighbourhoods, it became an accepted 'fact' (whether true or not) that gang members would threaten or murder anyone who cooperated with the police. At a homicide scene one of us attended, one witness repeatedly warned a second witness who was speaking with an investigator that 'the hills have eyes'. Investigators told us that citizens would rarely speak at crime scenes, but might call the investigator later or meet the investigator at a different location. We observed investigators routinely failing to canvass the area near the six homicide scenes we observed. When we asked them why, they told us they knew residents were afraid to talk to them and they did not want to place the residents at risk for reprisal.

Table 3. Homicide victims by age, 2001-2005.

\begin{tabular}{ccccccc}
\hline Year & $\begin{array}{c}\text { Under } 15 \\
(\%)\end{array}$ & $15-24(\%)$ & $25-34(\%)$ & $35-44(\%)$ & $45+(\%)$ & Average \\
\hline 2001 & 5.5 & 18.5 & 30.8 & 20.5 & 24.7 & 35.7 \\
2002 & 2.4 & 29.4 & 27.1 & 17.6 & 23.5 & 35.1 \\
2003 & 2.7 & 30.2 & 28.4 & 20.9 & 17.8 & 32.6 \\
2004 & 1.2 & 31.0 & 29.1 & 17.8 & 20.9 & 33.8 \\
2005 & 3.1 & 33.8 & 29.6 & 17.9 & 15.6 & 31.4 \\
\hline
\end{tabular}


Table 4. Homicide victims by sex, 2001-2005.

\begin{tabular}{ccc}
\hline Year & Female $(\%)$ & Male (\%) \\
\hline 2001 & 18.5 & 81.5 \\
2002 & 11.7 & 88.3 \\
2003 & 15.4 & 84.6 \\
2004 & 9.2 & 90.8 \\
2005 & 10.3 & 89.7 \\
\hline
\end{tabular}

Interviews with citizens, neighbourhood surveys and national opinion polls support the investigators' claims that citizens are now less willing to aid investigations. During our interviews with residents of high-crime areas, citizens reported that they had heard of witnesses who had cooperated with a police investigation, and were later victimised because news about their cooperation somehow leaked back to local gang members. One citizen commented: 'I wouldn't report a murder under any circumstances. It's not safe'. Very few of the people we interviewed said they would provide information about gang-related crime to the police. As one citizen explained: 'If people think you are an informant, your life becomes a living hell'. Another told us that to survive in her community, 'you have to be quiet'. A survey conducted in a high-crime neighbourhood in July 2006, a few months after the time period of this study, found that $86 \%$ of residents believed that gangs will retaliate against people who report gang-related crime to the police (Johnson 2006). The same survey asked residents if they would be willing to assist police with an investigation if they were an eyewitness to a gang-related homicide. Only $56 \%$ of the residents reported they would be 'very' or 'somewhat likely' to assist the police. In addition, only one in ten said they would be 'very' or 'somewhat likely' to testify about the homicide in court.

Many citizens are even hesitant to provide information to the police via an anonymous tip line. In a 2003 survey of 700 Trinidadians, only 59\% of respondents said they would be 'certain' or 'very likely' to call the Crime Stoppers anonymous tip line if they had information that could help the police. About half of those who would not call Crime Stoppers expressed concerns about whether their name would remain confidential. Consider the remarks of one respondent: 'I need to be $100 \%$ convinced that this method is fool-proof before I use it. Every time someone stands up and says "I see," within 3 weeks the witness is found tied up and floating in a pond' (Mori International 2003). Citizens in our focus groups reported similar views. One said: 'It's supposed to be anonymous, but they trace numbers. They call you back and then you get killed or intimidated'.

Although the murder of potential witnesses may be a rare phenomenon, even a small number of witness killings may be sufficient to scare the population away from cooperating with the police. ${ }^{7}$ This may be especially true when those murders are featured prominently in the media. In the spring of 2006, a priest who witnessed a robbery was killed just before the suspects went to trial. Priests are typically thought to be 'off limits' to violent street crime, so news of this killing quickly made its way to citizens of Trinidad and Tobago. In another highly publicised case, a woman who was a material witness to a gang homicide merely criticised the gang in public and she was gunned down shortly thereafter. Both killings were publicised as reprisals for opposing the gangs and cooperating with the police. It may not take a large number of witness killings to convince the public that they are not safe. 
This wariness of cooperating with the police was compounded by tales of police harassment, brutality and incompetence. Citizens and even police officers recounted tales of police officers threatening and beating citizens and suspects. One government employee told us that police officers 'treat citizens like dogs'. A resident in one distressed community said police 'do nothing' and that 'they are a waste of time'. Another said 'you are safer with the bandits than the police'. During a focus group, a resident of one inner-city community said that police 'jack you up and curse you'. These legitimacy problems are discussed regularly in the nation's newspapers and on radio and television. Investigators told us that a common tactic used by homicide suspects (on trial) who had provided a written confession was to claim that the confession had been coerced by police officers (who supposedly either beat or threatened to beat the suspect). Investigators claimed that charges of police brutality were so salient to jury members that such tactics regularly resulted in acquittals.

In sum, our interviews with police administrators, investigators and citizens suggest that citizen willingness to cooperate with police or testify in court has waned considerably. Unfortunately, the only evidence we have to support this claim is anecdotal. If the claim is true, it is likely to have been a major contributor to the decline in clearances.

\section{Prosecutorial and judicial decision-making}

Not all environmental influences have to do with case characteristics and citizens. Other agencies in the criminal justice system are external to the police organisation and can therefore also be considered part of its environment. One hypothesis about changes in clearance rates is that 'back pressure' from the prosecutor's office or the courts might exert an influence. If prosecutors or judges made changes in the kinds of cases they were willing to lay charges in or adjudicate, these decisions could exert pressure on the police investigating the cases not to make arrests until certain (and perhaps more stringent) criteria were met. Although the hypothesis is plausible, we found no evidence for it in any of our interviews with Criminal Investigations Department (CID) officers, homicide investigators and police administrators. In fact, two people (a homicide investigator and an administrator) told us that a 2005 amendment to the 1994 Bail Act made it somewhat easier for the police to close cases by denying bail to a larger number of defendants (Bail Reform Act of 1994). When the courts refuse to grant bail, thereby keeping the accused behind bars, the police report that they have a better chance of securing witnesses who are willing to provide information and testify. We found no evidence that prosecutorial and judicial decision-making played a role in the decline in clearances.

\section{Organisational factors}

\section{Staffing}

Before November 2005, the TTPS relied on a loosely coupled system in which no single police unit was solely responsible for investigating every homicide. For example, a homicide could be investigated by a uniformed constable assigned to a police station, or by a generalised investigator assigned to one of nine divisional criminal investigation offices. Officers investigating homicide cases would often 
partner with investigators from the HBI. Before a substantial reorganisation of homicide investigation structures and processes in November 2005, it was evident that administrators and officers within TTPS did not have a clear or routine method for assigning the responsibility for investigating homicides to individuals or teams. After a considerable number of interviews, we found that station-house investigators were typically responsible for conducting homicide investigations, with investigators from the HBI playing an auxiliary role and assisting with homicide investigations when asked. If a CID officer was not available, other officers from within the station district, or an officer from the HBI took the lead in the investigation. This approach endured from the inception of the HBI in 1978 until a reorganisation in November 2005. This system of distributing responsibility for homicide investigations across so many people and units confounds our ability to determine whether changes in investigator workload might have contributed to the decline in clearances.

Are declines in clearance rates attributable to changes in the staffing or workload of the HBI? We examined data on the authorised strength of the HBI between 1988 and 2005 to address this possibility. ${ }^{8}$ These data include all personnel assigned to the HBI, including supervisors and administrators. Although including supervisors and administrators in the computation of caseload estimates could underestimate the actual number of homicide cases assigned to investigators, this concern is offset by the assignment of many homicide cases to investigators from outside the HBI prior to November 2005. Thus, we suspect that our data represent overestimates of the actual homicide caseloads in the HBI, not underestimates.

Figure 4 displays the mean caseload per HBI investigator between 1988 and 2005. During the homicide increase (from 2000 to 2005), the authorised size of the HBI increased twice. From 1995 to the end of 2001, the HBI had 19 authorised positions. In 2002 this number increased to 35 positions, and then in 2003 it increased to 41 positions. Overall, these increases kept the ratio of homicides to HBI personnel at a relatively stable level between a low of 4.88 homicides per HBI officer (in 2002) and a high of 9.39 (in 2005). For the period between 1988 and 1999 (prior to the start of the homicide increase in 2000), the mean ratio of homicides per officer was 7.06. During the homicide increase (between 2000 and 2005), the mean ratio of homicides per officer dropped to 6.74. Despite this decrease in overall mean caseloads, the clearance rate for homicides during this period also decreased. Thus we conclude that the decline in clearance rates during this time is not likely attributable to increases in the ratio of homicides to HBI investigators.

Unfortunately, we do not have any systematic way to estimate whether increasing workloads among investigators from the CID might have led to a drop in clearances. These officers are responsible for investigating a wide range of offence types, but only homicides are recorded reliably within the TTPS. Official data on other offence types are not usable due to erratic recording and reporting practices. ${ }^{9}$ Data obtained from interviews and observations of criminal investigators assigned to high-crime stations located in distressed areas suggests that their caseloads (including burglaries, robberies, shootings, woundings and homicides) were large and unmanageable. Unfortunately, we were unable to locate any reliably recorded data that would enable us to do a quantitative test of the relationship between general investigative caseloads and homicide clearances. Although we unfortunately have no systematic way to test the hypothesis that increasing caseloads among CID investigators contributed to the decline in clearance rates, field notes from our interviews and observations are filled 


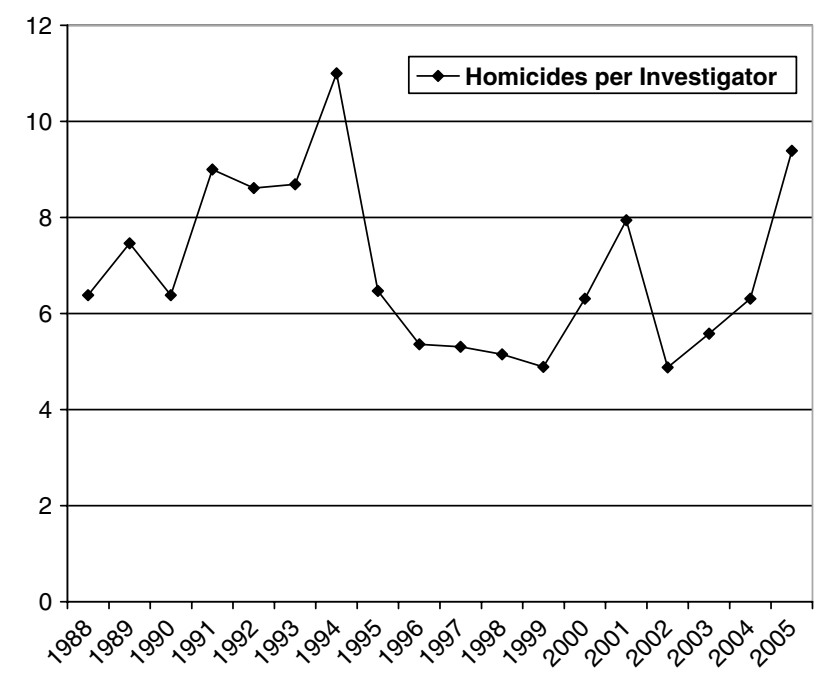

Figure 4. Homicides per HBI investigator, 1988-2005.

with anecdotal evidence to support this assertion. For instance, in July 2005 we interviewed three CID investigators from the police station district with the highest amount of violent crime in the country. Just over 6 months into the year, this district had already recorded 41 homicides in an area with a population of more than 38,000 . The district had only 15 detectives to handle not only these homicides but also every other offence type in the district. While homicides skyrocketed, their sworn strength remained static.

\section{Investigative characteristics}

We also examined whether there were any changes between 1988 and 2005 in investigative training or procedures which might account for the decline in clearance rates. Our interviews with police officials revealed that the majority of homicide investigators had never received formal training in homicide investigation until January 2006, after the substantial reorganisation of the HBI. A small number of investigators had attended investigator training in the USA before 2005, but we were unable to determine either the exact number of investigators who attended or the extent of that training. Police officials generally reported that it was too few investigators. Many of the officers we interviewed attributed the low homicide clearance rate to this lack of training. We find it difficult to accept this explanation, at least on its own, as a major contributor to the decline in clearance rates because the level of training did not change during the period of the homicide increase.

In fact, the homicide clearance rate was high for many years even with poorly trained investigators. It is possible that the lack of training only began to take its toll when the number of homicides expanded beyond a certain threshold - a 'tipping point' effect. We speculate that perhaps a small but competent number of investigators handled the bulk of homicides ably, but this group was unable to cope with the rising number of homicides. We do not have direct evidence to support this explanation, but patterns in the data are consistent with this interpretation. For 
instance, our analysis of 468 homicide cases in which a lead investigator was identified in case records showed that only about $26 \%$ of cases were handled by an investigator who had investigated seven or more homicides; only about $38 \%$ of cases were investigated by someone who had investigated five or more homicides. More than $26 \%$ of cases were handled by a lead investigator who had never led a homicide investigation before.

To determine the effects of previous experience in leading homicide investigations, we ran two types of analyses. First, we calculated non-parametric correlations between the number of previous cases investigated and whether the current case was cleared. The relationship was negative and statistically significant $(\rho=-0.166$, $\left.p<0.05 ; \tau_{b}=-0.142, p<0.001\right)$. Second, we estimated a binary logit model with case clearance as the dependent variable and number of previous homicide cases investigated as the independent variable. The results confirm that homicide case investigation experience has a significant negative effect on case clearances $(b=-0.092, p<0.001)$. Predicted probabilities calculated from the model estimates are useful for considering the magnitude of these effects. The predicted probability that investigators with no previous experience in leading a homicide investigation will clear the current case is 0.263 . The predicted probability for an investigator who has led five homicide cases drops to 0.198 , for 10 cases it is 0.135 and for 20 cases it is 0.059 . What accounts for this unexpected and counter-intuitive finding? One possible interpretation is a caseload effect; investigators with lots of previous experience in investigating homicides may have larger caseloads. Another possibility is that more difficult cases with a lower likelihood of being solved are assigned to more experienced investigators.

We also observed a lack of effective supervision and accountability within the HBI. During the fall of 2005, before the substantial reorganisation, we were unable to find any performance measures or performance standards established by managers that were used to evaluate the performance of those who investigate homicides. However, once again, we found no evidence that these conditions changed during the time that clearance rates dropped. We conclude that failures by supervisors to measure performance and hold investigators accountable did not help clearance rates, but these problems pre-dated the decline in clearance rates, and therefore constitute an unlikely explanation for the decline.

\section{Forensic evidence processing capacity}

In addition to information provided by citizens, homicide cases are often bolstered by the analysis of physical evidence. ${ }^{10}$ The capacity of police and other participating agencies to preserve, locate, collect, transport, analyse and store physical evidence may have a significant impact on their ability to clear homicide cases. Our research sheds some light on the extent to which physical evidence processing capacity contributed to the decline in homicide clearances in Trinidad and Tobago. It is hard to offer definitive proof that the decrease in homicide clearances in Trinidad and Tobago is due to the manner in which physical evidence was handled by the TTPS and the nation's crime lab, the Forensic Science Centre (FSC). Our observations, interviews and quantitative data analyses reveal a chequered pattern of processing physical evidence by both agencies. Overall, the TTPS was not properly organised to preserve and collect physical evidence at crime scenes, to transport that evidence to 
the FSC and to store that evidence and release it to officers for trial. Likewise, the FSC lacked the structure and management capacity to organise the processing of some evidence types (especially firearms evidence) and to manage the performance of laboratory personnel. These systematic problems likely existed before the marked increase in homicides in Trinidad and Tobago. However, before 2000, the systems for handling physical evidence in the TTPS and the FSC were sufficient (although likely inefficient) given the limited number of homicides per year. Like a leaky boat in calm seas, the employees of both organisations were able to bail water fast enough to remain afloat; the inefficiencies and insufficient policies and practices did not significantly impede the ability of police to clear homicide cases.

As the increase in homicides emerged in 2000, the sheer volume of physical evidence increased as well. The TTPS and FSC strained under the added burden of more cases; it was not possible to bail quickly enough. For example, starting in 2000 , the FSC began to amass a backlog of unprocessed firearms evidence. This backlog grew substantially each year and the firearms examiners fell further and further behind. With no system in place to prioritise cases, the examiners merely chiselled away at the oldest cases they had, regardless of whether the old cases had a suspect, were likely candidates for prosecution or police were awaiting the results of the analyses. More recent homicide cases were not prioritised, they were merely queued at the end of the backlog. Consequently, homicide investigators were not able to use evidence to link suspects to crimes, to leverage confessions from suspects or to support their charges in court.

As the FSC struggled to keep up with the increasing collection of unprocessed firearms evidence, it did not respond to this growing backlog. By late 2005, the backlog had ballooned to 2058 firearms cases and a much larger number of individual 'exhibits'. Yet the FSC's firearms section was only processing approximately 202 cases and 476 exhibits per year. By October 2005, the firearms backlog at the FSC was so large that we estimated it would take the firearms examiners 10 years to eliminate it at current staffing levels if they never received a new firearms case. ${ }^{11}$ This problem did not go unnoticed by police. One detective told us in October 2005: 'I have three rounds of ammo there [at the FSC] since 2001'. The detective explained in a frustrated tone that he had arrested a gang member for possession of ammunition. The only thing holding up the case was a certification by the FSC that the rounds were live. Yet he had been waiting for 4 years, during which time the suspect was free to commit other offences. We heard these kinds of complaints regularly, and unfortunately, these delays led some detectives to stop submitting ballistic evidence to the FSC.

Given that the vast majority of the increase in homicide cases was due to homicides by firearms, the inability of the FSC to process firearms evidence was a likely contributor to the decline in homicide clearances. In the absence of citizens willing to serve as witnesses and informants, physical evidence becomes more important for establishing probable cause and arresting suspects. Moreover, analyses from the FSC are probably seen as legitimate and scientific, and hence are more likely to influence those involved in court proceedings (such as judges, jurors and attorneys). In the absence of a report from the FSC, investigating homicides becomes still more difficult.

The role of photographers and draftsmen in homicide investigations was also problematic. Photographers for the TTPS are housed in a unit within the Criminal 
Records Office. These photographers are charged with attending and photographing homicide scenes along with other duties, such as photographing other crime scenes and capturing TTPS social events and functions. Our observations of these photographers at three homicide scenes during 2005 revealed that they arrived quickly and took photographs of the overall scene and some relevant pieces of physical evidence. However, when we later reviewed the photographs from these homicide scenes, we saw that some were out of focus while others failed to capture important pieces of evidence (in one case failing to capture a clear bloody footprint that one of us had photographed at the scene).

The TTPS also employs a number of 'draftsmen' who are charged with producing schematic diagrams (often called 'sketches' in the USA) of homicide scenes. Unfortunately, these draftsmen rarely attend the homicide scene itself. Thus, draftsmen can produce a sketch of the static objects (such as roadways, buildings and trees) located at a homicide scene, but they cannot place other objects (such as dead bodies, shell casings and blood spatters) accurately in these sketches. Some homicide scenes are sketched by other personnel at the scene (either detectives or fingerprint technicians), but our review of a handful of cases revealed that the sketches contain the barest of information, rarely include accurate measurements to locate physical evidence, and often exclude essential information (such as a compass rose, a title, the case name and number, etc.).

These problems in capturing evidence at homicide scenes in the form of photographs and sketches make it even more difficult to close homicide cases. We found little evidence that the production of crime scene sketches or photographs had changed during the time of the decline in homicide clearance rates. Overall, while crime scene sketches and photographs certainly did not exemplify best practices in homicide investigations, we cannot conclude that either led to the decrease in homicide clearance rates.

\section{Higher order effects}

Skogan (1990) argues that some communities become caught in a downward spiral of decay. The initial causes of that downward spiral are catalysts; once they produce their initial effects, the downward spiral often takes on a life of its own. We observed evidence of a similar catalytic effect influencing homicide clearance rates in Trinidad and Tobago, with environmental factors and organisational factors influencing one another (a reciprocal relationship) and interacting with one another (a multiplicative relationship). For example, lengthy delays in forensic evidence processing led some investigators not to submit physical evidence, especially ballistic evidence, to the FSC. Without this evidence, the FSC could not link ballistic evidence to crimes and criminals, which not only decreased clearance rates, but also presumably led some active offenders to continue offending. Similarly, as clearance rates dropped, citizen confidence in the ability of the police to protect them from retaliation by offenders decreased, producing lower levels of citizen cooperation. As citizens shared less information with police, investigators stopped doing neighbourhood canvasses and eliciting information from citizens. By pulling back, police investigators ensured that they would not receive useful information from communities, and with less contact, citizen confidence in the police continued to drop. 
Inherent in these explanations are direct, indirect, reciprocal and multiplicative effects on clearances. For instance, delays in forensic evidence processing have a direct impact on the ability of police to clear homicide cases, but they also have an indirect effect by leading police not to submit physical evidence for processing. This simultaneous set of influences is likely to operate interactively in addition to the separate and independent effects of the factors we examined in this paper. Put more simply, we suspect that when all of these things occur simultaneously, like the consequences of a 'perfect storm' of multiple weather systems coming together, they intensify the inability of the police to solve cases. For example, although a gangmotivated homicide is difficult to solve, and a firearms homicide with missing ballistic evidence is also difficult, the two sets of circumstances together make it especially unlikely in Trinidad and Tobago that the case will be solved. These higher order effects are difficult to specify a priori in the quantitative models tested in previous research, since learning about them in the first place requires the kinds of up-close and personal research that we carried out in Trinidad and Tobago. The idea of interaction effects contributing to the decline in homicide clearances in Trinidad and Tobago is reminiscent of Bowling's (1999, p. 547) account for the decrease in homicide in New York during the 1990s: 'a plausible explanation for part of the reduction in homicide ... is the interaction between the shifts in the drug market on one hand and changes in policing on the other'.

\section{Conclusion and implications}

The purpose of the present study was to identify factors associated with the substantial decrease in homicide clearance rates in Trinidad and Tobago. From 1999 to 2005 , the number of homicides increased by $314 \%$, and homicide clearance rates decreased from more than $70 \%$ to about 24\%. Data from 2006 to 2009 suggest that the clearance rate continued to drop even more after the study period. In this paper, we examined a series of internal and external factors that are likely to influence homicide clearance rates. This section reviews our findings, provides a larger context for understanding them and outlines their implications for improving homicide clearance rates.

Some of the reasons for the decrease in homicide clearances in Trinidad and Tobago were external or environmental, related to the substantial change in the nature of the homicide problem during the period of the study, as well as the relationship between police and other agencies in the criminal justice system. Others were clearly internal or organisational, due to limitations in the capacity of the police to carry out effective homicide investigations. According to contingency theory, effective organisations detect and adapt to changes in their environment to remain effective. Ineffective organisations either fail to adapt or they adapt in dysfunctional ways (Langworthy 1986, Maguire 2003). In this section, we discuss how the interplay between organisational and environmental factors led to a precipitous drop in homicide clearances.

As the number of homicides increased, there was a simultaneous shift in case characteristics with an increasing proportion of the homicides involving gangs and guns. Domestic homicides, which are among the easiest to solve, began to constitute a much smaller share of total homicides. Prior research has shown that gang homicides are often less likely to be solved than other homicides, due largely to the 
unique characteristics of these offences. Gang homicides usually involve the use of firearms, take place in public places, and offenders and victims typically have little personal contact with one another. Maxson et al. (1985) argue that the unique nature of gang homicides often requires police to rely on local gang experts for help in solving homicides. These gang experts are able to provide homicide investigators with valuable information and intelligence on turf, rivalries, alliances, membership lists, on-going disputes and other forms of intelligence that can assist investigators in identifying potential suspects and motives. Jurisdictions faced with high numbers of gang and gun homicides sometimes establish specialised structures such as gang intelligence units or specialised ballistic evidence processing units to help them clear these cases.

In other words, although changes in case characteristics are 'external', agencies can adapt internally, developing new capacities to meet these external demands. Our findings suggest that the nation of Trinidad and Tobago did not have the appropriate infrastructure in place to respond to a large increase in the number of homicides. Perhaps most importantly, the TTPS did not have sufficient organisational or management practices for the routine, expert processing of homicide investigations. Instead, homicide investigations were left to those generalised station-house constables and criminal investigators who 'caught the case'. These officers reported being unable to devote much time to homicide investigations because they were burdened with large caseloads containing many types of offences. To be clear, no single organisational unit or person in the police agency was formally specified as responsible or accountable for investigating homicides. This problem was further exacerbated by the fact that those who investigated homicides in Trinidad and Tobago had very little formal training in homicide investigations or crime scene management. Furthermore many of them did not have any experience investigating homicides.

Additionally, Trinidad and Tobago's criminal justice system did not have the proper infrastructure in place for collecting information necessary to clear cases, such as witness statements, proper descriptions of crime scenes, photographs and physical evidence. It became clear during our interviews that the police believed the community was unwilling to provide information to the police that might help them solve violent crimes. This belief was so acculturated in the police organisation that we routinely observed officers at homicide scenes no longer even attempting to interview nearby citizens and witnesses. They did not conduct canvasses, record names, leave business cards or engage in other steps typically taken in other nations for cultivating witnesses. Similarly, physical evidence, even when it was collected, was often packaged or secured improperly. Furthermore, due to the enormous backlog of ballistic evidence at the FSC, crucial evidence for solving homicides was typically unavailable to investigators.

Our findings suggest that as the number of homicides increased precipitously, the response to homicides in Trinidad and Tobago became increasingly disjointed and poorly coordinated, much as one would expect when any organisation manages to perform adequately in a 'normal' environment but lacks the capacity to respond to a rapidly emerging crisis. Before the rise in homicides, the nation's infrastructure for investigating homicides was sufficient, routinely generating homicide clearance rates on par with developed nations like the USA, Britain, Japan, Canada and Australia. However, once the number of homicides began to increase sharply, the existing 
organisational structures and processes became overwhelmed. This appears to be attributable ultimately to a lack of management capacity. Because there was no clear division of labour or system of accountability for investigating homicides, the police service itself lacked the capacity to plan, organise, staff and coordinate an effective response to the growing problem. This generalised lack of capacity was made even more difficult because the police did not have a contingent of officers trained to process crime scenes, and preserve and collect physical evidence necessary to solve cases.

Furthermore, a lack of interagency coordination and cooperation between the police and the nation's crime laboratory exacerbated the problem significantly. Both the TTPS and the FSC had insufficient organisational capacities for clearing homicide cases. Neither agency responded to the many clearly visible warning signals that homicides were increasing and clearances were dropping. But in addition to these problems with organisational capacity were problems with the relationship between agencies (and even units within these agencies). The two agencies did not engage in any kind of on-going collective strategic planning to determine how they would work together to solve the problem. These two agencies, and the units and divisions within them, lacked the 'network of capacity' to deal with the rising epidemic of homicides (Moore 2002, p. 338). Research on developing nations reveals this to be a common issue. The reasons why fire hydrants run dry, food becomes scarce and vaccinations do not make their way to those who need them most sometimes have very little to do with 'external' problems like resource constraints. Often these are organisational problems, reflecting a poorly developed internal capacity within individual organisations. Even more importantly, they sometimes reflect a poorly developed capacity for responding collectively by the network of agencies responsible for dealing with some share of a larger social problem. Such was the case with homicides in Trinidad and Tobago.

Healthy organisations adapt their internal technologies dynamically to keep up with changes in their environment. Healthy governments go one step further, not only nurturing the individual capacities of their employees and their agencies, but engineering the collective capacities of these people and agencies to work together effectively. One of the reasons that homicide clearance rates fell in Trinidad and Tobago is that the nature of homicide changed suddenly. Healthy systems with a capacity for adjusting to sudden changes or 'environmental jolts' might have been able to respond to this external shock (Meyer 1982). In Trinidad and Tobago, the system for responding to homicides lacked the capacity to endure or adapt to sudden changes. Even 5 years after the dramatic increase in homicides, there were no appreciable changes in how the system was organised or how it responded. Neither the people responding to homicide, the organisations that employed those people, nor the institutions responsible for overseeing and guiding them, had implemented any major reforms to enhance their capacity for clearing homicide cases.

The interface between external changes in the character and number of homicides, and a lack of internal capacity for dealing with these external changes, produced the precipitous drop in homicide clearance rates. While the external factors are not easily manipulable, the internal ones can be changed. The challenge for criminal justice agencies and those who attempt to reform them - especially in developing nations - is to develop the internal capacity to react to these external changes. The rapid decline in homicide clearances was not solely a problem of either 
legal institutions or the larger society - it was a problem that developed at the interface of the two. The solution, as with many social problems, is putting in place legal structures and processes capable of detecting changes in the criminal environment and reacting properly to those changes when they are detected.

\section{Acknowledgements}

Funding for this research was provided by the Ministry of National Security of Trinidad and Tobago. Portions of this research were approved by the Human Subjects Review Board (HSRB) at Bowling Green State University under Project \# H09P242EE5; other portions were deemed exempt from review by the HSRB. The points of view expressed in this paper are those of the authors alone and do not represent the official policies or positions of the Ministry of National Security or the Trinidad and Tobago Police Service.

\section{Notes}

1. A long tradition of research has pointed out that clearance rates are 'susceptible to manipulation and measurement error' (Cordner 1989, p. 146). Thus, the conceptual meaning of a homicide clearance rate is not always clear. Yet, given the much lower reporting rates for other offence types, we suspect clearance rates for homicide are significantly clearer by comparison.

2. Here we use the term 'technology' in the same way it is used by organisation theorists, to refer to the methods or processes used by an organisation to accomplish its work (Maguire 2003).

3. Police agencies can lose 'business' or 'market share' to other competing organisations such as private security corporations (Bayley and Shearing 1996). Yet they are unlikely to lose responsibility for something as specialised and consequential as homicide investigations unless they refer such cases to other police agencies that are larger and have more expertise.

4. Although the Pearson correlation coefficient is unbiased for time series data, the standard errors are typically biased because adjacent observations are not independent. Therefore, we do not present a statistical significance test.

5. There are three reasons for our suspicion about data on homicide motives. First, the criteria for classifying motives are not clearly established. Second, the current system only allows for the selection of a single motive when in reality there are often multiple motives. Third, criminal intelligence on homicides is sometimes inconsistent with official homicide classifications.

6. For this analysis (and others that follow), we only had access to longitudinal data that started after homicides had already begun to rise and clearances had begun to drop. These data series are not ideal because they do not capture a longer range of variation; nonetheless, they are still useful for capturing some meaningful changes in the short run.

7. Police intelligence data collected by the authors in 2006 on the motives and suspects in homicide cases from two high-crime areas suggests that reprisal killings are not common. In the 53 cases where police intelligence was sufficient to pinpoint a motive, only three cases $(5.7 \%)$ involved killing a potential witness. Interpreting this figure is difficult. On the one hand it may suggest that citizen fears of reprisals against witnesses may be overstated. On the other hand, it is possible that a sufficient number of witnesses may have been killed in previous years to dissuade witnesses from coming forward. If this is true, we would expect the current number of witness reprisals to be low. It is also possible that the police lack the capacity to know whether or why citizens are reluctant to talk to them. If citizens are reluctant to talk to the police about homicides due to fear of intimidation, perhaps police intelligence files would not contain accurate classifications of witness killings.

8. Our interviews indicate that there is sometimes a large disjuncture between authorised and actual strength within TTPS units. Unfortunately, data on actual strength were simply not available over time. If the scope of the discrepancy between actual and authorised strength 
remained stable, then our data are reliable but not valid, and therefore still potentially useful. However, we have no way to diagnose whether the error is stable over time.

9. Our examination of criminal records at the division and station levels shows that diligence in recording crimes known to police varies dramatically across geographic units and over time for serious crimes other than homicide.

10. The forensic evidence processing capacity is partially an organisational influence and partially an environmental influence. The TTPS has responsibility for locating, preserving and transporting the evidence and so these steps in the process can be considered internal to the organisation. However, another agency external to the police, the Forensic Science Centre, has responsibility for processing the evidence. That portion of forensic evidence processing which takes place externally can be considered an environmental influence.

11. After the study period, the FSC brought in some foreign firearms examiners on a temporary contract to eliminate the backlog.

\section{References}

Addington, L.A., 2006. Using national incident-based reporting system murder data to evaluate clearance predictors: a research note. Homicide Studies, 10 (2), 140-152.

Alderden, M. and Lavery, T., 2007. Predicting homicide clearances in Chicago: investigating disparities in predictors across different types of homicides. Homicide Studies, 11 (2), 115132.

Alpert, G.P. and Moore, M.H., 1993. Measuring police performance in the new paradigm of policing. In: J.J. Dilulio, Jr., ed. Performance measures for the criminal justice system. Washington, DC: U.S. Department of Justice, Bureau of Justice Statistics, 109-142.

Bail (Amendment) (No. 2) Act, 2005. An Act to amend the Bail Act, 1994. Act No. 18 (September 1994).

Bayley, D.H. and Shearing, C.D., 1996. The future of policing. Law and Society Review, 30 (3), 585-606.

Black, D., 1976. The behavior of law. Orlando, FL: Academic Press.

Borg, M. and Parker, K.F., 2001. Mobilizing law in urban areas: the social structure of homicide clearance rates. Law and Society Review, 35 (2), 435-466.

Bowling, B., 1999. The rise and fall of New York murder. British Journal of Criminology, 39 (4), 531-554.

Chaiken, J., Greenwood, P., and Petersilia, J., 1977. The rand study of detectives. Policy Analysis, 3 (2), 187-217.

Cordner, G.W., 1989. Police agency size and investigative effectiveness. Journal of Criminal Justice, 17, 145-155.

Crank, J.P., 2003. Institutional theory of police: a review of the state of the art. Policing: an International Journal of Police Strategies and Management, 26 (2), 186-207.

Crank, J.P. and Langworthy, R., 1992. An institutional perspective of policing. Journal of Criminal Law and Criminology, 83 (2), 338-363.

Davies, H., 2007. Understanding variations in murder clearance rates: the influence of political environment. Homicide Studies, 11 (2), 133-150.

Donaldson, L., 1995. American anti-management theories of organization: a critique of paradigm proliferation. Cambridge: Cambridge University Press.

Hasenfeld, Y., 1992. Theoretical approaches to human service organizations. In: Y. Hasenfeld, ed. Human service as complex organizations. Newbury Park, CA: Sage, 24-44.

Hoffman, R.B., 1971. Performance measurements in crime control. Journal of Research in Crime and Delinquency, 8 (2), 165-174.

Innes, M., 2003. Investigating murder: detective work and the police response to criminal homicide. New York: Oxford.

Jiao, A., 2008. Explaining homicide clearance: an analysis of Chicago homicide data, 19651995. Criminal Justice Studies, 20 (1), 3-14.

Johnson, D., 2006. Preliminary survey results from the Gonzales IMPACT Study. Unpublished research report. George Mason University, September 2006.

Katz, C.M., 2001. The establishment of a police gang unit: an examination of organizational and environmental factors. Criminology, 39 (1), 37-75. 
Keel, T., Jarvis, J., and Muirhead, Y., 2008. An exploratory analysis of factors affecting homicide investigations: examining the dynamics of murder clearance rates. Homicide Studies, 13, 50-68.

Langworthy, R.H., 1986. The structure of police organizations. New York: Praeger.

Lee, C., 2005. The value of life in death: multiple regression and event history analyses of homicide clearance in Los Angeles County. Journal of Criminal Justice, 33 (6), 527-534.

Litwin, K.J., 2004. A multilevel multivariate analysis of factors affecting homicide clearances. Journal of Research in Crime and Delinquency, 41 (4), 327-351.

Litwin, K. and $\mathrm{Xu}, \mathrm{Y} ., 2007$. The dynamic nature of homicide clearances: a multilevel model comparison of three time periods. Homicide Studies, 11 (2), 94-114.

Maguire, E.R., 2003. Organizational structure in large police agencies: context, complexity, and control. Albany, NY: State University of New York Press.

Maguire, E.R., et al., 2008. Spatial concentrations of violence in Trinidad and Tobago. Caribbean Journal of Criminology and Public Safety, 13 (1-2), 44-83.

Marche, G.E., 1994. The production of homicide solutions: an empirical analysis. American Journal of Economics and Sociology, 53 (4), 385-401.

Maxson, C., Gordon, M., and Klein, M., 1985. Differences between gang and non-gang homicides. Criminology, 23 (2), 209-222.

Meyer, A.D., 1982. Adapting to environmental jolts. Administrative Science Quarterly, 27, 515-537.

Meyer, M.W. and Zucker, L.G., 1989. Permanently failing organizations. Newbury Park, CA: Sage.

Moore, M.H., 2002. Creating networks of capacity: the challenge of managing society's response to youth violence. In: G. Katzmann, ed. Securing our children's future. Washington, DC: The Brookings Institution, 338-385.

Mori International, 2003. Opinion leaders panel 2003: wave 3 report. Port of Spain, Trinidad: Government of Trinidad and Tobago.

Mouzos, J. and Muller, D., 2001. Solvability factors of homicide in Australia: an exploratory analysis. Trends and issues in crime and criminology, No. 216. Canberra: Australian Institute of Criminology.

Nadel, S.W., 1978. Measurement systems and organizational goals in a large metropolitan police department. Police Studies, 1 (4), 39-45.

Poggio, E.C., et al., 1985. Blueprint for the future of the Uniform Crime Reporting program: final report of the UCR study. Washington, DC: U.S. Department of Justice.

Puckett, J.L. and Lundman, R.J., 2003. Factors affecting homicide clearances: multivariate analysis of a more complete conceptual framework. Journal of Research in Crime and Delinquency, 40 (2), 171-193.

Regoeczi, W.C., Kennedy, L.W., and Silverman, R.A., 2000. Uncleared homicides: a Canada/ United States comparison. Homicide Studies, 4, 135-161.

Riedel, M. and Jarvis, J., 1998. The decline of arrest clearances for criminal homicide: causes, correlates and third parties. Criminal Justice Policy Review, 9, 279-305.

Riedel, M. and Rinehart, T.A., 1996. Murder clearances and missing data. Journal of Crime and Justice, 19, 83-102.

Riggs, F.W., 1964. Administration in developing countries: the theory of prismatic society. Boston, MA: Howard Mifflin.

Roberts, A., 2007. Predictors of homicide clearance by arrest: an event history analysis of NIBRS incidents. Homicide Studies, 11 (2), 82-93.

Roberts, A., 2008. Explaining differences in homicide clearance rates between Japan and the United States. Homicide Studies, 12 (1), 136-145.

Ryan, G.W. and Bernard, H.R., 2000. Data management and analysis methods. In: N.K. Denzin and Y.S. Lincoln, eds. Handbook of qualitative research. 2nd ed. Thousand Oaks, CA: Sage, 769-802.

Schroeder, D.A. and White, M.D., 2009. Exploring the use of DNA evidence in homicide investigations: implications for detective work and case clearance. Police Quarterly, 12, 319342.

Skogan, W.G., 1990. Disorder and decline: crime and the spiral of decay in American neighborhoods. Berkeley, CA: University of California Press. 
Wellford, C. and Cronin, J., 1999. An analysis of variables affecting the clearance of homicides: a multistate study. Washington, DC: Justice Research and Statistics Association.

Willis, J.J., Mastrofski, S.D., and Weisburd, D., 2007. Making sense of COMPSTAT: a theorybased analysis of organizational change in three police departments. Law and Society Review, 41 (1), 147-188.

$\mathrm{Xu}$, Y., 2008. Characteristics of homicide events and the decline in homicide clearances: a longitudinal approach to the dynamic relationship, Chicago, 1966-1995. Criminal Justice Review, 33 (4), 453-479. 